\title{
ATINGIDOS POR BARRAGENS E COTIDIANO: CONCRETUDE, TRANSFORMAÇÃO E RESISTÊNCIA ${ }^{1}$
}

Resumo: Pensar o cotidiano como um espaço de múltiplas intersecções, onde os sujeitos estabelecem práticas, saberes, táticas e subterfúgios é o objetivo deste artigo. Através de um diálogo entre teóricos deste assunto, procura-se contribuir para a difusão desta categoria de análise dentro dos estudos historiográficos. Os sujeitos se constituem nas diversas experiências do vivido, nas diversas relações de poder e na pluralidade de tempos e espaços que podem ser percebidas na pesquisa do seu cotidiano. Neste sentido, uma "hermenêutica do cotidiano" dos atingido por barragens pode favorecer a uma escrita historiográfica de resistências, transformações e concretudes.

Palavras-chave: história, cotidiano, atingidos por barragens.

\footnotetext{
${ }^{1}$ Agradeço imensamente a Dr ${ }^{\mathrm{a}}$ Yonissa Marmitt Wadi pelas inúmeras contribuições neste artigo e na pesquisa e aos consultores desta revista pela revisão e questionamentos.

${ }^{2}$ Mestrando em História pela Universidade Federal de Santa Catarina. Membro do Grupo de Pesquisa Cultura Relações de Gênero e Memória da Universidade Estadual do Oeste do Paraná - UNIOESTE / Campus de Toledo.cezark@hotmail.com
} 


\section{Revista Alamedas - Revista Eletrônica do NDP \\ V.1, n.1, jan./jun.2006 - ISSN 1981-0253}

\section{Introdução}

O presente artigo faz parte de uma revisão bibliográfica sobre as possibilidades de uma história do cotidiano. A proposta é um diálogo entre esses pressupostos teóricos e um estudo específico de uma pesquisa sobre atingidos por barragens. Trata-se de um estudo que ainda está em andamento e tem como objetivo acompanhar as experiências dos sujeitos que tiveram suas vidas modificadas diante da construção da Usina Hidrelétrica (UHE) de Salto Caxias, região Oeste e Sudoeste do Paraná, nos anos de 1990. Especificamente aqueles que não aderiram ao Movimento Social "Comissão Regional dos Atingidos por Barragens do Rio Iguaçu - CRABI" e permaneceram às margens do reservatório.

Historicizar o processo de implantação de hidrelétrica sob a ótica daqueles sujeitos que não migraram é um dos objetivos deste estudo. Neste sentido, a proposta de se pensar o seu cotidiano, com sua historicidade, mudanças e permanências poderá estabelecer novas questões sobre a categoria "atingidos por barragens".

Neste artigo buscou-se dialogar com teóricos que defendem a escrita de uma história do cotidiano. Segundo esses pressupostos, o cotidiano emerge "enquanto um espaço de mudança, resistência ao processo de dominação, define um campo social de múltiplas interseções de fatores que contribuem decisivamente para transcender categorias e polaridades". (Dias, 1992, p.51).

Para facilitar, dividiu-se o artigo em duas partes. Na primeira parte, historiciza-se de modo sucinto a construção da UHE de Salto Caxias, as formas de indenização e a proposta da pesquisa. Na segunda parte procurou-se contextualizar o objeto de pesquisa na perspectiva de uma história do cotidiano num diálogo com alguns autores.

\section{A usina hidrelétrica de Salto Caxias: especificidades e questionamentos}




\section{Revista Alamedas - Revista Eletrônica do NDP V.1, n.1, jan./jun.2006 - ISSN 1981-0253}

Segundo dados oficiais, no dia 26 de março de 1999 o Governo do Paraná mostrou para a sociedade brasileira uma de suas maiores conquistas tecnológicas: a Usina Hidrelétrica (UHE) de Salto Caxias. Um empreendimento que custou 1 bilhão de dólares e que garante para 4 milhões de pessoas o benefício da energia elétrica até o ano de $2015 .{ }^{3}$ Com técnicas avançadas, os engenheiros conseguiram bloquear o Rio Iguaçu em pouco tempo e com a maior racionalização possível de seus recursos energéticos. A barragem fez emergir um lago de 131 $\mathrm{km}^{2}$ que engoliu vilas, propriedades rurais, casas, lavouras, escolas, capelas, florestas, etc. Um espaço historicamente constituído dá lugar a uma paisagem artificialmente constrúda.

Até aqui, talvez nenhuma novidade àqueles que se embrenham no estudo das barragens e dos seus atingidos, porém, Salto Caxias reserva uma especificidade capaz de fazer-nos pensar algumas questões nesse emaranhado de passos técnicos e objetivos que se dá na construção de uma UHE.

Enquanto se erguiam as paredes da barragem com os enormes blocos de concreto, uma batalha se estabeleceu às margens do rio que seria represado. De um lado estava a Companhia Paranaense de Energia (Copel) que precisava retirar da área as 1.025 famílias cujas propriedades seriam diretamente atingidas pelo alagamento; do outro lado uma organização popular liderada pelos atingidos sob os ideais do Movimento dos Atingidos por Barragens (MAB) que exigiam seus direitos e estudavam a melhor maneira de serem ressarcidos pela perca de suas propriedades.

Esse movimento popular se fortaleceu com sua bandeira de luta e com a participação de inúmeros atingidos capazes de marchar dias a fio para embargar a obra e exigir indenização justa. Sua força se tornou notória e a ‘ameaça do povo’ fez a Copel recuar e apresentar inúmeros projetos de indenização. No interior da organização, os líderes conclamam a sociedade a partilhar de seu movimento de luta que se identificaria como Comissão Regional dos Atingidos

${ }^{3}$ COMPANHIA PARANAENSE DE ENERGIA. Usina Hidrelétrica de Salto Caxias. Disp. em (http://home.copel.com:9090/PagCopel.nsf/docsap/BE9D34467AAF883403256B760042E91F?OpenDocument \&secao $=$ GER $\% 3$ Ausinas\%3Ahidreletricas\&). Acesso em 22/06/04 


\section{Revista Alamedas - Revista Eletrônica do NDP V.1, n.1, jan./jun.2006 - ISSN 1981-0253}

pelas Barragens do Rio Iguaçu - CRABI. Com o estigma de serem atingidos pelas barragens do Rio Iguaçu, e com os ideais do MAB e do MST, a CRABI surge como um porta-voz dos atingidos e a legítima defensora dos seus direitos.

Nos enfrentamentos com a Copel a CRABI exigiu um plano de indenização que visasse a permanência dos atingidos na terra, pois o trabalho na agricultura era o que todos tinham em comum. Para o movimento o reassentamento era a forma mais justa de se indenizar os atingidos e era isso o que reivindicavam.

Depois de muitas discussões, a Copel elaborou um projeto inédito de indenização: os atingidos poderiam escolher entre reassentamento ou carta de crédito. ${ }^{4} \mathrm{O}$ reassentamento possibilitaria o 'transplante' dos atingidos para outras localidades e a carta de crédito era a possibilidade da indenização em dólar. Como já exposto, para o movimento social, o reassentamento era a forma de indenização correta, pois significava uma vitória no processo de construção de barragens já que os atingidos poderiam estabelecer-se em outras áreas de terra. $\mathrm{O}$ foco da luta a partir daí foi a escolha destas propriedades e as exigências sobre essas áreas.

Das 1.025 famílias com direito de escolha, 600 optaram pelo reassentamento e 425 pela carta de crédito, ou seja, por mais que o movimento social reivindicasse o reassentamento em nome dos atingidos, uma parcela significativa destes - cerca de $41,5 \%$ - não quis ser reassentada. A partir do momento da escolha, os caminhos dos atingidos tomam rumos bem diferentes.

Aqueles que escolheram o reassentamento continuaram sob a 'proteção' do movimento social que, instituído e forte, continuou fazendo suas reivindicações. A CRABI tomou para si a luta pela implantação de um reassentamento que fosse capaz de prover todas as necessidades dos seus membros. E, de certa forma, conseguiu, pois o reassentamento da UHE de Salto Caxias é modelo mundial de refoma agrária no discurso do Estado e do Movimento Social.

\footnotetext{
${ }^{4}$ Para maiores detalhes sobre as formas de indenização propostas pela Copel cf. KARPINSKI, C. A Usina de Salto Caxias e a história dos que ficaram: princípios de uma pesquisa. Informativo do Núcleo de Documentação e Pesquisa da Unioeste/Campus de Toledo, Toledo - PR, v. 2, n. 2, p. 6, 2003. Disponível em: http://www.unioeste.br/ndp/Informativo\%20NDP\%20II.pdf
} 


\section{Revista Alamedas - Revista Eletrônica do NDP V.1, n.1, jan./jun.2006 - ISSN 1981-0253}

Porém, não existe ainda um estudo sobre os atingidos que optaram pela carta de crédito. Não se sabe ao certo o que fizeram aqueles que se negaram a participar do novo e audacioso método indenizatório de reassentamento.

O movimento social tomou para si o título de defensor dos direitos dos atingidos com a autoridade de quem resistia aos ditames da Copel, porém, a resistência, no movimento, se deu num processo de migração, ou seja, a população foi retirada do local no tempo exato que a Copel queria que isso acontecesse.

Inúmeros problemas poderiam ser expostos neste momento, contudo, esta pesquisa se propõe analisar as especificidades desses sujeitos que receberam suas cartas de crédito e adquiriram suas novas propriedades nas proximidades do reservatório. Percebe-se que esta condição de não-pertencimento fez desses sujeitos meros coadjuvantes no processo de resistência, historicizado até agora sobre o processo de implantação daUHE de Salto Caxias.

\section{“Começar de novo...": o cotidiano como possibilidade nos estudos históricos}

Com o acúmulo de água para formação do reservatório, a população que preferiu ficar na região atingida se deparou com uma multiplicidade de temporalidades. Junto ao novo ambiente artificial que ora fascina, ora assunta, os ribeirinhos se deparam com antigas lembranças, do "como era antes" daquilo que "jamais voltará a ser". Apesar de seus sentimentos, incertezas e memórias, há de se "começar de novo...”, ou re-começar.

Neste sentido é que se torna extremamente pertinente nesta pesquisa a história do cotidiano. Pois é este que estabelece a concretude do próprio fato, ou seja, o cotidiano é a condição de possibilidade para o estudo das transformações e resistências realizadas pelos sujeitos históricos. E são essas transformações que marcam determinado tempo e espaço, que são os fundamentos do própró devir histórico.

$\mathrm{Na}$ particularidade do estudo sobre os atingidos que não migraram e continuam nas cidades lindeiras ao reservatório de Salto Caxias, tais sujeitos estão engendrados num processo 


\section{Revista Alamedas - Revista Eletrônica do NDP V.1, n.1, jan./jun.2006 - ISSN 1981-0253}

de temporalidades múltiplas e relativas ao seu próprio tempo, pois algo do passado não os deixou migrar e no presente os faz reconstruir, reelaborar, substituir e formular novas formas de viver num ambiente extremamente modificado por fatores exógenos. A construção da Usina se apresenta como um fato do presente, mas que não apaga utopias, sonhos e idealizações que aqueles sujeitos construíram através do tempo naquele espaço. É nesta mistura de temporalidades que aparecem novas experiências que podem ser percebidas no estudo do seu cotidiano.

Estabelecer como se constituíram estes sujeitos que não migrarem neste processo de indenização é uma das questões chaves a ser pesquisada. A resposta poderá até demonstrar uma outra forma de se pensar a resistência. E, se pensarmos na questão como um estudo de mudança, de rupturas, de novos modos de ser, estaremos abrigados justamente no conceito contemporâneo de cotidiano. Pois, são nas práticas de sobrevivência com suas táticas e subterfúgios que se emerge o cotidiano sempre em processo de ser re-inventado. (Certeau, 1996)

Segundo Dias (1998), o cotidiano deve emergir nas pesquisas históricas como um espaço daquilo que não é dado na historiografia oficial, ou seja, estudar o cotidiano implica em desbravar o novo, o singular, o heterogêneo, o subjetivo, justamente aquilo que foi homogeneizado na perspectiva de uma classe dominante. Essa emersão do cotidiano na pesquisa historiográfica por sua vez não é inventada pelo historiador, ou seja, é concretude que se revela aos olhares aguçados e não viciados. A distinção em uma pesquisa de sujeitos historicamente excluídos na prática de seu cotidiano é justamente o olhar com que o historiador vai perceber suas práticas e relações sociais. Interpretar esse emaranhado de concretude, transformação e resistência que se dão no cotidiano será o diferencial capaz de estabelecer o heterogêneo, pois os sujeitos são distintos, são específicos eparticulares.

No movimento social em que os atingidos se apoiaram para o reassentamento, mesmo sendo um espaço múltiplo e subjetivo, os sujeitos tornam-se peças de um discurso que tenta 


\section{Revista Alamedas - Revista Eletrônica do NDP V.1, n.1, jan./jun.2006 - ISSN 1981-0253}

homogeneizar as práticas destes atingidos, ou seja, criam-se estratégias que podem em pouco tempo, modificar as práticas individuais para atender aos moldes de um espaço tecnicamente criado para um fim específico. No caso dos reassentamentos o discurso hodierno é a prática da agricultura familiar cooperativista capaz de tornar seus produtos competitivos no mercado o que torna possível a vida do homem no campo.

Com aqueles que ficaram, o processo é um pouco diferente, pois são eles os responsáveis pela transformação de seu espaço nos moldes que eles mesmos estabelecerem, mesmo que influenciados por outros fatores. A postura destes sujeitos demonstra uma individuação e uma configuração de novas atitudes que refletem uma resistência talvez silenciosa ou silenciada às políticas energéticas do nosso país. Mesmo tendo que mudar de suas vilas devido ao alagamento, pelo menos a possibilidade de adquirir propriedades próximas quer mostrar uma liberdade de permanecer. Esses acontecimentos favorecem a uma ação política diante da construção da barragem. Como afirma Heller (1985, p.41) "apesar da mímese e da alienação inerente à vida quotidiana, é sempre possível a individuação e a configuração de novas atitudes. O quotidiano envolve uma margem de liberdade, certa possibilidade de equilíbrio entre a individualidade e o ser genérico".

Segundo Dias (1992, p.50), são essas relações entre o pormenor e o global, minúcias e conjuntos do processo social que implicam na ação dos agentes históricos que escapam ou fogem dos papéis formais, às normas e às instituições. No caso de Salto Caxias a resistência à migração e conseqüentemente ao movimento social que quis o reassentamento, estabelece justamente isso. A CRABI se transformou em uma instituição de direito capaz de estabelecer o que era melhor aos atingidos. A não-adesão a essas idéias, correndo inclusive o risco de serem 'esquecidos' pelas políticas de desenvolvimento faz daqueles que ficaram sujeitos distintos dessa história.

Para Dias (1992 p.50), essas diferenças é que definem “a busca da especificidade histórica, que nunca é produto de racionalidades, pois admite o contingencial, o fortuito, a 


\section{Revista Alamedas - Revista Eletrônica do NDP \\ V.1, n.1, jan./jun.2006 - ISSN 1981-0253}

inventividade, a liberdade de ação dos agentes históricos. É o que justamente torna possível vislumbrar, na interpretação do processo histórico, a reinvenção de um futuro libertário e não mera inferência de necessidades estruturais".

Sendo assim, a hermenêutica do cotidiano desses atingidos que não migraram é, sem dúvida, um caminho para conhecimentos novos, concretos e diferenciados num espaço onde inúmeros fatores - temporalidades, memória, religiosidade, utopias, mercado, políticas, etc. - se entrecruzam. Certamente é neste campo de 'múltiplas interseções' que se estabelece a própria história.

\section{Referências}

CERTEAU, M. A invenção do cotidiano: artes de fazer. 2ª ed. Petrópolis : Vozes, 1996.

DIAS, M. O. L. S. Hermenêutica do quotidiano na historiografia contemporânea. Revista Proj. História São Paulo, n.17, 1998

DIAS, M. O. L. S. Teoria e método dos estudos feministas: perspectiva histórica e hermenêutica do cotidiano. In: COSTA, A. ; BRUSCINI, C. Uma questão de gênero. Rio de Janeiro : Rosa dos tempos, 1992.

HELLER, A. O cotidiano e a história. Rio de Janeiro : Paz e Terra, 1985. 